\title{
Associations of familial risk factors with social fears and social phobia: evidence for the continuum hypothesis in social anxiety disorder?
}

\author{
Susanne Knappe $\cdot$ Katja Beesdo $\cdot$ Lydia Fehm • \\ Roselind Lieb · Hans-Ulrich Wittchen
}

Received: 13 March 2008/Accepted: 20 August 2008/Published online: 4 November 2008

(C) The Author(s) 2008. This article is published with open access at Springerlink.com

\begin{abstract}
We examined parental psychopathology and family environment in subthreshold and DSM-IV threshold conditions of social anxiety disorder (SAD) in a representative cohort sample of 1,395 adolescents. Offspring and parental psychopathology was assessed using the DIA$\mathrm{X} / \mathrm{M}$-CIDI; recalled parental rearing and family functioning via questionnaire. Diagnostic interviews in parents were supplemented by family history reports from offspring. The cumulative lifetime incidence was $23.07 \%$ for symptomatic SAD, and 18.38 and $7.41 \%$ for subthreshold and threshold SAD, respectively. The specific parent-tooffspring association for SAD occurred for threshold SAD only. For subthreshold and threshold SAD similar associations were found with other parental anxiety disorders, depression and substance use disorders. Parental rearing behaviour, but not family functioning, was associated with offspring threshold SAD, and although less strong and less consistent, also with subthreshold SAD. Results suggest a continued graded relationship between familial risk factors
\end{abstract}

S. Knappe $(\bowtie) \cdot$ K. Beesdo $\cdot$ H.-U. Wittchen

Institute of Clinical Psychology and Psychotherapy,

Technische Universitaet Dresden, Chemnitzer Str. 46,

01187 Dresden, Germany

e-mail: knappe@psychologie.tu-dresden.de

L. Fehm

Department of Psychology, Humboldt University Berlin,

Berlin, Germany

R. Lieb

Epidemiology and Health Psychology,

University of Basel, Basel, Switzerland

R. Lieb · H.-U. Wittchen

Clinical Psychology and Epidemiology,

Max Planck Institute of Psychiatry, Munich, Germany and offspring SAD. Parental psychopathology and negative parental styles may be used defining high-risk groups to assign individuals with already subthreshold conditions of SAD to early intervention programs.

Keywords Social phobia - Social anxiety disorder . Parental psychopathology · Family environment .

Continuum

\section{Introduction}

Social Phobia, also known as social anxiety disorder (SAD), is characterized by a marked and persistent fear of at least one social or performance situation, in which the person is exposed to the scrutiny of others and where embarrassment or humiliation might occur (American Psychiatric Association 1994). DSM-IV SAD is one of the most prevalent and burdensome mental disorders with a mean lifetime prevalence of $6.7 \%$ in European (Fehm et al. 2005) and up to $12.1 \%$ in US-samples (NCS-R; Kessler et al. 2005). SAD has its onset typically in early adolescence (Beesdo et al. 2007; Lépine et al. 1993; Magee et al. 1996; Merikangas et al. 2002; Kessler et al. 2005; Wittchen et al. 2001) and often persists into adulthood (Chartier et al. 1998; Keller 2006). Findings from prospective studies indicate low diagnostic stability on the DSM-IV threshold level, but also a low likelihood of full remission from DSM-IV SAD, and frequent shifts of SAD symptoms around the diagnostic threshold (Emmelkamp and Wittchen 2008; Merikangas et al. 2002). Accordingly, prevalence rates of those who suffer from social fears below the DSM-IV diagnostic threshold range nearly up to $25 \%$ in general population samples (Davidson et al. 1994; Egger and Angold 2006; Fehm et al. 2008; Milne et al. 1995; Ruscio et al. 2008; 
Wittchen et al. 1999). Social fears below the diagnostic threshold are comparable to DSM-IV threshold SAD in terms of associated impairment, disability in various domains of daily living (Davidson et al. 1994; Fehm et al. 2008; Keenan et al. 1997; Stein et al. 2000), and development of comorbid/subsequent anxiety, depression and substance use disorders (Crum and Pratt 2001; Merikangas et al. 2002; Zhang et al. 2004). Social fears below the diagnostic threshold are further associated with an increased risk for progression into DSM-IV threshold SAD (Costello et al. 1999; Ialongo et al. 1995), and thereby are a sensitive and useful indicator for later psychopathology and substantial impairment in psychosocial functioning. Thus, early diagnosis of first SAD symptoms may assist in the prevention of more severe psychiatric symptoms.

Parental SAD and other parental mental disorders, negative parental rearing styles (Lieb et al. 2000b; Turner et al. 2003; Woodruff-Borden et al. 2002), and problematic family functioning or attachment (Bögels et al. 2001; Hudson and Rapee 2001) have been suggested as important risk factors for DSM-IV threshold SAD. However, it remains unclear to what degree these familial risk factors may also contribute to SAD below the diagnostic threshold. The aim of the present study is therefore to examine the associations of parental psychopathology, parental rearing and family functioning with subthreshold and threshold SAD. Findings are based on a cohort of 1,395 adolescents from a representative community sample aged 14 to 17 years that was followed-up prospectively across the high risk period for the SAD onset from early adolescence into the third decade of life. Results of the present study may also contribute to the question of whether social fears below the diagnostic threshold are part of a continuum of severity or rather represent a discrete phenomenon with more or less arbitrarily derived thresholds distinct from DSM-IV threshold SAD. Implications from these results for clinical practice will be discussed.

\section{Materials and methods}

Sample

Data were collected as part of the prospective longitudinal Early Developmental Stages of Psychopathology (EDSP)study. The EDSP-study is designed as a random regional representative population sample of a German community in the metropolitan area of Munich to study the natural course of early stages of substance use and other mental disorders and to identify risk factors for their onset and course. Detailed descriptions of the EDSP design and field procedures are reported elsewhere (Lieb et al. 2000a; Wittchen et al. 1998). The study consists of a baseline survey conducted in 1995 (T0) with $N=3,021$ individuals (response rate $71 \%$ ) of a younger (aged 14-17 years at baseline) and an older study cohort (18-24 years at baseline). The first follow-up (T1) was conducted approximately 2 years after baseline only for the younger cohort (mean interval 1.64 years, $\mathrm{SD}=0.19$, range 1.2 2.1) $(N=1,228$; response rate $87.8 \%)$. The second (T2) $(N=2,548$, mean interval 3.47 years, $\mathrm{SD}=0.25$, range $2.8-4.1$, response rate: $84.3 \%$ ) and third follow-up (T3) $(N=2,210$, mean interval 8.38 years, $\mathrm{SD}=0.65$; range 7.4-10.6, response rate: $73 \%$ ) were conducted approximately 4 and 10 years after baseline for both cohorts. In this study, we refer to the younger study cohort aged 14-17 at baseline (T0: $N=1,395, \quad \mathrm{~T} 1: \quad N=1,228 ; \quad \mathrm{T} 2$ : $N=1,169$; T3: $N=1,022$ ), because family environment variables were only assessed in the younger subsample. No selective drop out (attrition) from baseline (T0: $N=1,395$ ) to 10-year follow-up (T3: $N=1,022$ ) occurred for SAD $(\mathrm{OR}=0.5,95 \%$ CI $0.3-1.1)$.

A key feature of the EDSP-Study is a special family supplement (EDSP-FS; Lieb et al. 2000a) to investigate familial contributions to the development of mental disorders in offspring. Primarily, the mothers were interviewed. Fathers were interviewed if the mother was not available (lack of time, deceased or not locatable). Parents of 1,053 offspring, namely, in 1,026 cases the mother, and in 27 cases the father (response rate $86 \%$ ), were interviewed directly.

The EDSP project and its family genetic supplement have been approved by the Ethics Committee of the Medical Faculty of the Technische Universitaet Dresden (No: EK-13811). All participants provided written informed consent.

\section{Diagnostic assessment}

Assessment of offspring psychopathology

Mental disorders were assessed with the computer-assisted version of the Munich-Composite International Diagnostic Interview (DIA-X/M-CIDI) (Wittchen and Pfister 1997), an updated version of the World Health Organization's CIDI version 1.2 (WHO 1990, 1992). Participants were interviewed face to face by trained clinical interviewers.

The DIA-X/M-CIDI allows for the standardized assessment of symptoms, syndromes and diagnoses of 48 mental disorders according to DSM-IV and ICD-10 criteria along with information about the onset, duration, and severity. All diagnoses are based on the DSM-IV/DIA-X algorithms. Reliability and validity are moderate to good for all the disorders covered by the DIA-X/M-CIDI (Lachner et al. 1998; Reed et al. 1998). Test-retest reliability for the SAD module is acceptable (kappa $=0.57$; Reed et al. 1998). 
At baseline, the DIA-X/M-CIDI was used to assess lifetime and 12-month diagnoses. The follow-up surveys administered a modified version of the DIA-X/M-CIDI that covered the time interval since the last interview. To increase validity, respond lists regarding possible situations of social fears and a list of social fear symptoms were used (Wittchen et al. 2001).

The diagnostic status of offspring was categorized into four mutually exclusive groups using the highest diagnostic status across all waves. Offspring who positively affirmed exclusively the DIA-X/M-CIDI stem-question for "ever having a persistent, irrational fear of, and compelling desire to avoid a situation in which the respondent attended social affairs, like going to a party or meeting", were labelled as symptomatic SAD. Offspring were asked to give a concrete example for each item endorsed to allow for clarification. For subthreshold SAD, additionally a marked and persistent fear of social or performance situations in which the person is exposed to unfamiliar people or to possible scrutiny by others (criterion A) and three of the following criteria had to be fulfilled: Exposure to social or performance situations almost invariably provokes an immediate anxiety response (criterion $\mathrm{B}$ ), individuals recognize that their fear is excessive or unreasonable (criterion $\mathrm{C}$ ), the feared situations are avoided or else are endured with intense distress (criterion D), and social fears interfere significantly with psychosocial functioning (criterion $\mathrm{E}$ ). If all DSM-IV criteria (A, B, C, D, and E) were met, a threshold SAD diagnosis (DSM-IV) was assigned. As estimation of impairment due to SAD may be of limited reliability in respondents of younger age, for this study, the impairment criterion (E) was only required for an SAD diagnosis, when respondents were 18 years or older. Individuals, who denied the stem question, were classified as non-socially anxious.

\section{Assessments of parental psychopathology}

Diagnostic information on parental psychopathology was derived from both direct and indirect sources. Direct interviews were conducted with one or both parents at the first follow-up, indirect information were collected by family history reports from their offspring at baseline.

Parents' direct interviews were assessed using the DIA$\mathrm{X} / \mathrm{M}$-CIDI. All interviews were conducted by trained clinical interviewers who were blind to the diagnostic findings of their offspring. Most interviews took place in the parents' homes, separate from their offspring. Indirect parental diagnoses were derived from family history data collected with the offspring as informants using the MCIDI family history module according to the Family History Research Diagnostic Criteria (Andreasen et al. 1977). Offspring were asked M-CIDI—questions to assess the key symptoms of parental DSM-IV disorders and whether their parent sought professional help because of his or her respective symptoms.

\section{Assignment of parental diagnoses}

Parental diagnoses (SAD, any other anxiety disorder, depressive disorders, alcohol use disorders) were estimated on the basis of a priori established algorithms, analogue to Lieb et al. (2000b). A parental diagnosis was assigned when positive diagnostic information was available from direct diagnostic interviews or family history information. When no indications of parental diagnoses from any of the two sources were given, parents were classified to have "no diagnosis". According to their diagnoses parents were classified into four groups: parents with SAD with or without comorbid disorders, parents with other anxiety disorders than SAD (panic disorder, agoraphobia, generalized anxiety disorder, simple phobia, and obsessive compulsive disorder), parents with depressive disorders excluding SAD (major depressive disorder and dysthymia), and parents with alcohol use disorders excluding SAD (alcohol abuse or dependence). Lieb et al. (2000b) reported low sensitivity, but high specificity of agreement between directly assessed parental diagnoses and family history data.

\section{Assessment of family environment}

Parenting style was assessed in offspring at first follow-up with the Questionnaire of Recalled Parental Rearing Behaviour (German: Fragebogen zum Erinnerten Elterlichen Erziehungsverhalten, FEE, Schumacher et al. 1999, original by Perris et al. 1980), administered to offspring. The FEE assesses three dimensions of offsprings perceived parental rearing behaviour, namely, parental rejection, emotional warmth, and overprotection. Reliability and validity of the FEE have been reported to be high. The German Version of the McMaster family assessment device (FAD, Arrindel et al. 1994) was used to assess six dimensions of family functioning, namely, problem solving, communication, role behaviour, affective responsiveness, affective involvement, and behaviour control, in directly interviewed parents at first follow-up. The FAD provides scores for each of these subscales and also a 'general functioning scale', representing the overall 'family climate'. The questionnaire is based on the McMaster Model of Family Functioning and its reliability and validity have been well established (Kabacoff et al. 1990).

Statistical analysis

Offspring diagnostic information from the four assessment waves was aggregated for observed cumulative lifetime 
incidences (CLI; T0, T1, T2, and T3), using the last observation carried forward (LOCF) method. Analyses are based on respondents for whom information about parental psychopathology was available $(N=1,053)$. Associations between parental psychopathology, parental rearing behaviour, and family functioning with offspring SAD were assessed with odds ratios (ORs) from multinomial logistic regressions, controlled for age and gender. Analyses were done using Stata 10.0 (StataCorp 2007). Results (percentages, ratios, coefficients) are weighted for age, gender, geographic location, non-contact and nonresponse to match the distribution of the sampling frame (Lieb et al. 2000a); frequencies $(N)$ are reported unweighted.

\section{Results}

Cumulative lifetime incidences up to age 28 for SAD

Observed cumulative lifetime incidence up to age 28 (maximum age of oldest respondents at last wave) was $7.41 \%(N=82 / 1,053)$ for DSM-IV threshold SAD, and $18.38 \%(N=190 / 1,053)$ and $23.07 \%(N=244 / 1,053)$ for subthreshold and symptomatic SAD, respectively. Females were significantly more often affected by threshold SAD (8.96 vs. $5.90 \%, \quad \mathrm{OR}=1.92, \quad 95 \%$ CI $1.16-3.20$, $P=0.012)$ and subthreshold SAD (21.89 vs. $14.96 \%$, $\mathrm{OR}=1.83,95 \%$ CI $1.28-2.60, P=0.001)$ than males. For symptomatic SAD, no gender difference was found $(22.50$ vs. $23.66 \%, \quad \mathrm{OR}=1.32, \quad 95 \%$ CI $0.95-1.82$, $P=0.099)$.

Parental psychopathology and the risk for offspring SAD

Among the 1,053 mothers and fathers, $N=137$ parents (134 mothers and 3 fathers) met criteria for SAD, $N=385$ parents (375 mothers and 10 fathers) reported any other anxiety disorder, $N=384$ parents (368 mothers and 16 fathers) reported any depressive disorder, and $N=299$ parents (288 mothers and 11 fathers) reported any alcohol use disorder. In sum, $N=793$ parents (769 mothers, 24 fathers) were affected by any of these disorders, and only $N=260$ parents (257 mothers and 3 fathers) reported no anxiety, depressive or alcohol use disorder. The latter group served as reference group for the following comparisons.

As shown in Table 1, the proportion of offspring affected by SAD and whose parents are affected by psychopathology themselves increased with the diagnostic level of offspring SAD (column percentages). Among offspring without SAD, $12.10 \%$ had parents with SAD.
For offspring with symptomatic, subthreshold and DSMIV threshold SAD, rates of parental SAD were 13.77, 11.67 and $17.41 \%$, respectively. Rates of affected parents similarly increased with the diagnostic status of offspring SAD when parents were affected by other anxiety disorders (range 53.72-80.42\%), depressive disorders (range $53.80-78.42 \%$ ), or alcohol use disorder (range 47.87$73.89 \%)$.

Table 1 additionally shows the associations between parental psychopathology and offspring SAD status (row percentages, ORs), indicating the risk for offspring SAD when parents are affected by SAD, any other anxiety disorder, depressive disorders or alcohol use disorder in comparison to offspring of unaffected parents. For symptomatic $S A D$ in offspring, no associations with parental psychopathology were found. For subthreshold SAD in offspring, associations with other parental anxiety disorders $(20.82 \%, \mathrm{OR}=1.92,95 \%$ CI: $1.17-3.16, P=0.010)$, depressive disorders $(22.25 \%, \mathrm{OR}=1.99,95 \%$ CI $1.21-$ 3.26, $P=0.006)$ and alcohol use disorder $(21.71 \%$, $\mathrm{OR}=1.96,95 \%$ CI $1.16-3.30, P=0.011)$ were found. Offspring of parents with SAD did not report higher rates of subthreshold SAD $(16.75 \%$, OR $=1.44,95 \%$ CI: $0.75-$ 2.78, $P=0.271)$, compared to offspring of unaffected parents $(13.54 \%)$. Relative to symptomatic SAD, associations between parental psychopathology and offspring subthreshold SAD were not substantially higher (results not shown in table; parental SAD: OR $=1.11,95 \%$ CI 0.54 2.28, $P=0.771$; other parental anxiety disorders: $\mathrm{OR}=1.51, \quad 95 \% \quad$ CI $0.85-2.69, \quad P=0.156$; parental depressive disorders: $\mathrm{OR}=1.70,95 \%$ CI $0.96-3.00$, $P=0.070$; parental alcohol use disorder: $\mathrm{OR}=1.67,95 \%$ CI $0.91-3.05, P=0.098)$.

Strongest associations with parental SAD occurred for offspring DSM-IV threshold SAD (10.08\%, OR $=3.21$, 95\% CI 1.21-8.49, $P=0.019)$ in comparison to offspring of unaffected parents $(3.65 \%)$. Because also other parental anxiety disorders $(10.13 \%, \mathrm{OR}=3.44$, 95\% CI 1.58 7.53, $P=0.002)$, depressive disorders $(9.11 \%$, $\mathrm{OR}=3.02,95 \%$ CI $1.35-6.59, P=0.007)$, and alcohol use disorder $(8.89 \%, \mathrm{OR}=3.07,95 \%$ CI 1.34-7.03, $P=0.008)$ were substantially associated with offspring DSM-IV threshold SAD, the specific parent-to-offspring association for SAD was controlled for other parental psychopathology. However, the association remained marginally significant $(\mathrm{OR}=1.30,95 \%$ CI $1.00-1.71$, $P=0.057)$. Noteworthy, associations between parental psychopathology and offspring DSM-IV threshold versus subthreshold SAD did not differ for parental SAD (results not shown in table; parental SAD: $\mathrm{OR}=2.34$, 95\% CI $0.78-7.02, P=0.131)$, or for other parental anxiety disorders $\quad(\mathrm{OR}=1.83,95 \% \quad$ CI $0.76-4.39, \quad P=0.178)$, depressive disorders $(\mathrm{OR}=1.76,95 \%$ CI $0.76-4.39$, 


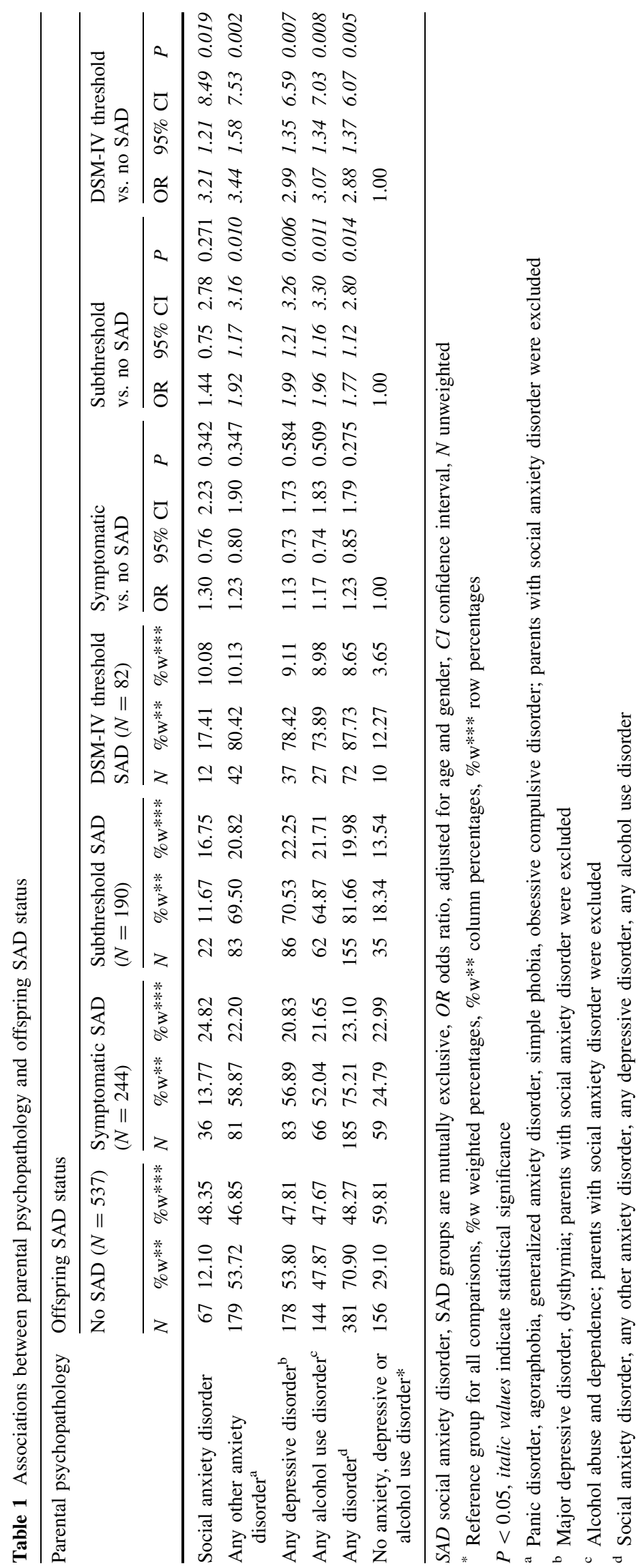


$P=0.178)$ or alcohol use disorder $(\mathrm{OR}=1.77,95 \% \mathrm{CI}$ $0.68-4.62, P=0.244)$.

Overall, associations between parental psychopathology and offspring SAD status were independent of offspring age or gender.

Family environment and the risk for offspring SAD

For offspring with symptomatic SAD, no associations with recalled parental rearing behaviour occurred (Table 2). Offspring with subthreshold SAD reported more parental overprotection $\quad(\mathrm{OR}=1.08, \quad 95 \% \quad \mathrm{CI}: \quad 1.01-1.16$, $P=0.021)$ and more parental rejection $(\mathrm{OR}=1.12,95 \%$ CI $1.01-1.25, P=0.043$ ) than offspring without SAD. In comparison to threshold SAD, offspring with subthreshold SAD reported less rejection $(\mathrm{RR}=0.84,95 \%$ CI $0.72-$ $0.98, P=0.024)$, and marginally less overprotection $(\mathrm{RR}=0.91,95 \%$ CI $0.83-1.01, P=0.058)$.

Offspring with $D S M-I V$ threshold $S A D$ reported significantly more parental overprotection $(\mathrm{OR}=1.19,95 \% \mathrm{CI}$ 1.09-1.30, $P=0.000)$, more parental rejection $(\mathrm{OR}=1.34,95 \%$ CI $1.15-1.55, P=0.000)$, and less emotional warmth $(\mathrm{OR}=0.90,95 \%$ CI $0.83-0.97$, $P=0.007)$ than their non-socially phobic counterparts (Table 2). Overall, perceptions of negative parental rearing styles increased with the diagnostic status of offspring SAD.

Analyses of the family functioning scales revealed no associations between any specific scale and offspring SAD. Therefore, only the overall general functioning scale score is reported in Table 2 .

As parental psychopathology and parental rearing may influence each other, we controlled the associations between parental psychopathology and offspring SAD for parental rearing (Table 3, upper part), as well as the associations between parental rearing and offspring SAD for parental psychopathology (Table 3, lower part). This did not alter the associations.

\section{Discussion}

The present study examined the associations of parental psychopathology and familial environment with subthreshold and threshold conditions of SAD in a cohort study of a representative community sample of adolescents and young adults. The major finding of our study is that associations of parental psychopathology and negative parental rearing styles with social fears increased in magnitude towards the DSM-IV threshold, suggesting a continued graded relationship between familial risk factors and SAD in offspring.

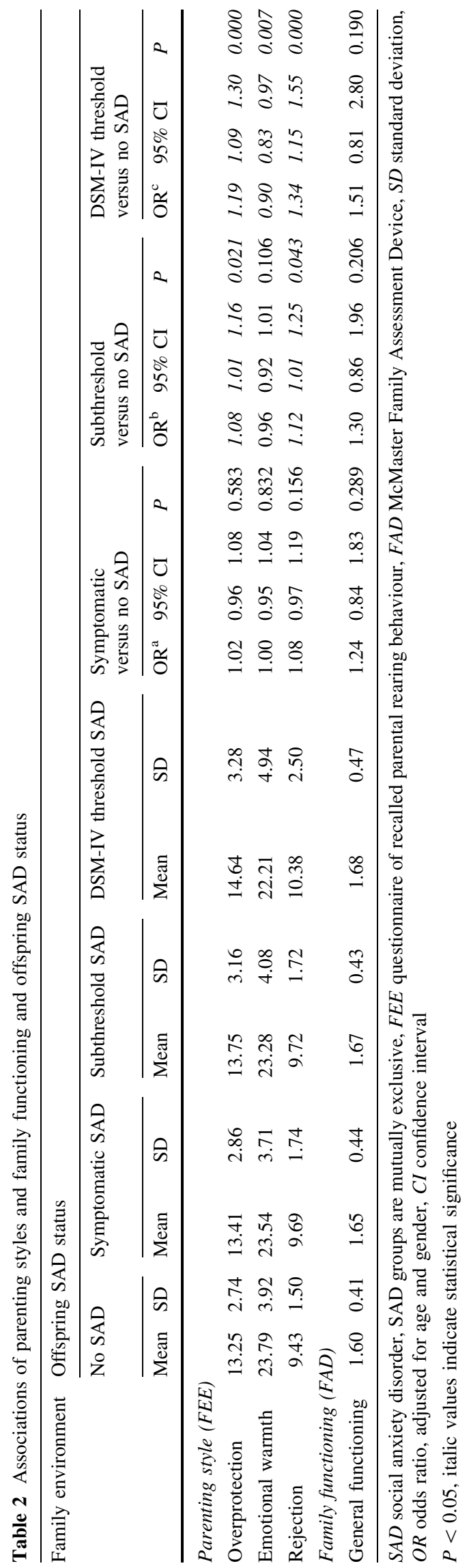


Table 3 Associations between parental psychopathology, parenting style and offspring SAD status

\begin{tabular}{|c|c|c|c|c|c|c|c|c|c|c|c|c|}
\hline & \multicolumn{12}{|c|}{ Offspring SAD status } \\
\hline & \multicolumn{4}{|c|}{ Symptomatic SAD } & \multicolumn{4}{|c|}{ Subthreshold SAD } & \multicolumn{4}{|c|}{ DSM-IV threshold SAD } \\
\hline & OR & $95 \% \mathrm{C}$ & & $P$ & OR & $95 \% \mathrm{C}$ & & $P$ & OR & $95 \%$ & & $P$ \\
\hline \multicolumn{13}{|c|}{ Parental psychopathology status, controlled for parenting style (FEE) } \\
\hline Social anxiety disorder & 1.32 & 0.75 & 2.36 & 0.338 & 1.43 & 0.71 & 2.92 & 0.319 & 3.27 & 1.14 & 9.34 & 0.027 \\
\hline Any other anxiety disorder ${ }^{a}$ & 1.26 & 0.79 & 2.02 & 0.326 & 2.01 & 1.18 & 3.44 & 0.011 & 3.02 & 1.31 & 6.98 & 0.010 \\
\hline Any depressive disorder ${ }^{\mathrm{b}}$ & 1.15 & 0.73 & 1.82 & 0.539 & 1.94 & 1.14 & 3.31 & 0.015 & 2.71 & 1.16 & 6.34 & 0.022 \\
\hline Any alcohol use disorder ${ }^{\mathrm{c}}$ & 1.19 & 0.73 & 1.93 & 0.490 & 1.91 & 1.08 & 3.38 & 0.026 & 2.86 & 1.18 & 6.97 & 0.021 \\
\hline Any disorder ${ }^{\mathrm{d}}$ & 1.25 & 0.84 & 1.88 & 0.273 & 1.80 & 1.09 & 2.95 & 0.021 & 2.74 & 1.23 & 6.12 & 0.014 \\
\hline \multicolumn{13}{|c|}{ Parenting style (FEE), controlled for parental psychopathology } \\
\hline Overprotection & 1.02 & 0.96 & 1.08 & 0.584 & 1.08 & 1.01 & 1.16 & 0.021 & 1.18 & 1.08 & 1.29 & 0.000 \\
\hline Emotional warmth & 1.00 & 0.96 & 1.04 & 0.875 & 0.96 & 0.92 & 1.01 & 0.130 & 0.91 & 0.84 & 0.98 & 0.012 \\
\hline Rejection & 1.08 & 0.97 & 1.19 & 0.159 & 1.12 & 1.00 & 1.25 & 0.048 & 1.33 & 1.15 & 1.54 & 0.000 \\
\hline
\end{tabular}

$S A D$ social anxiety disorder, SAD groups are mutually exclusive, FEE questionnaire of recalled parental rearing behaviour, $O R$ odds ratio, adjusted for age and gender, comparison group are offspring without parental psychopathology (upper part) and offspring without SAD (lower part), respectively, $C I$ confidence interval

$P<0.05$, bold values indicate statistical significance

${ }^{\text {a }}$ Panic disorder, agoraphobia, generalized anxiety disorder, simple phobia, obsessive compulsive disorder; parents with social anxiety disorder were excluded

b Major depressive disorder, dysthymia; parents with social anxiety disorder were excluded

c Alcohol abuse and dependence; parents with social anxiety disorder were excluded

${ }^{\mathrm{d}}$ Social anxiety disorder, any other anxiety disorder, any depressive disorder, any alcohol use disorder

Consistent with previous family studies (Fyer et al. 1993; Hettema et al. 2001; Kendler et al. 1999; Lieb et al. 2000b; McClure et al. 2001; Stein et al. 2001), parental SAD was associated with offspring DSM-IV threshold SAD, but not with subthreshold or symptomatic SAD. However, associations with other parental anxiety, depressive or alcohol use disorders were found for DSM-IV threshold as well as for subthreshold SAD in similar magnitude. Noteworthy, controlling the specific SAD parent-offspring association for other parental disorders did not substantially change the findings. Current knowledge regarding the specificity of the intergenerational transmission of SAD is still scarce and heterogeneous (e.g. Fyer et al. 1993; but see Cooper et al. 2006), likely due to the fact that SAD frequently co-occurs with other disorders, and pure (non-comorbid) cases are rare. Our results indicate low to moderate specifity for the intergenerational transmission of SAD: the specific parentto-offspring association for SAD remained significant also after controlling for other parental disorders. Nevertheless, other parental psychopathology (other anxiety, depressive, substance use disorders) were similarly associated with DSM-IV threshold SAD, but also with subthreshold SAD. From that, the familial aggregation of SAD may likely also be determinated by cross-disorder risk factors (Johnson et al. 2006), as well as family based developmental conditions.

Concordant with prior studies (Bandelow et al. 2004; Bögels et al. 2001; Lieb et al. 2000b; Taylor and Alden
2006; Woodruff-Borden et al. 2002), offspring reports of higher parental overprotection, rejection and lower emotional warmth were associated with DSM-IV threshold SAD. Although attenuated in magnitude, and less consistently for emotional warmth, offspring with subthreshold SAD similarly reported a more negative parental rearing, probably reflecting their SAD risk status. However, it remains unclear whether offspring reports of parental rearing correspond to actual 'pathological parenting' or, instead, rather reflect an information processing (Christensen et al. 2003; Heerey and Kring 2007; Voncken et al. 2006) or attributional bias (Alfano et al. 2006; Taylor and Wald 2003; Wilson and Rapee 2005) in offspring with SAD. Given that our findings did not change after controlling for parental psychopathology and that parental reports of family functioning were not associated with the risk for SAD in offspring, offspring perceptions of negative parental rearing may merely reflect their psychopathology.

Overall, our findings point to similarities and differences between subthreshold and threshold SAD. Subthreshold and threshold SAD were similarly associated with parental psychopathology, except for parental SAD. Also, offspring negative perceptions of family environment were similarly associated with subthreshold and threshold SAD, except for the lack of emotional warmth. Thus, parental psychopathology and familial environmental conditions may both be useful in identifying individuals at risk for subthreshold 
and threshold SAD. In addition, there may be doseresponse relationship between familial risk factors and offspring SAD status as indicated by the increasing magnitude of associations towards the DSM-IV diagnostic threshold. It will be of interest for future research to investigate, in a more detailed manner, whether a certain number or pattern of risk factors is associated with subthreshold or threshold SAD. Importantly, prospective analyses to identify the temporal relationship of parental psychopathology, parental rearing and the transition from subthreshold to threshold SAD status are needed.

The present findings may also contribute to the discussion about whether social fears below and above the diagnostic threshold represent a continuum of severity (Kessler et al. 2003) or are discrete phenomena with more or less arbitrarily derived thresholds. Mild to moderate social fears are an almost universal experience, and it is crucial to find the balance between under-recognition and under-treatment of SAD on the one hand, and overpathologizing SAD symptoms on the other hand (Wakefield et al. 2005). Previous research indicated that even social fears below the diagnostic threshold are associated with high comorbidity (Fehm et al. 2008; Merikangas et al. 2002; Zhang et al. 2004), impairment and disability (Davidson et al. 1994; Keenan et al. 1997; Stein et al. 2000), comparable to DSM-IV threshold SAD. Individuals at risk for SAD may shift across a continuum for SAD liability (Kendler et al. 1999), depending on the number or kind of risk factors that are present. A continuum-hypothesis would also more precisely reflect the natural, oscillating course of the disorder (Merikangas et al. 2002; Spitzer 1998; Wittchen and Fehm 2003). A broadened conception of SAD would have the advantage of increasing the statistical power of studies examining potential genetic and environmental risk factors for the development of excessive social fears.

Our results should also be discussed in the light of several limitations. At first we could not examine if the offspring risk for SAD in general and for DSM-IV threshold SAD in particular is additionally increased when both parents are affected (as compared to one affected parent) due to the low prevalences of affected fathers. A second limitation concerns the retrospective assessment of parental rearing, although the majority of adolescents still lived with their parents at the time of assessment.

In conclusion, the current study confirms the importance of familial risk factors for SAD in a representative community sample of adolescents and young adults. Important novel findings indicate that (1) the graded relationship between familial risk factors and offspring SAD status provides further evidence for a continuum of social fears and social phobia, (2) there may be a doseresponse relationship between familial risk factors and diagnostic status of SAD in offspring, and (3) the specific intergenerational transmission of SAD between parents and their offspring is modest and may be limited to DSMIV threshold SAD. Given the associated burden of social fears below the diagnostic threshold, parental psychopathology and offspring perceptions of the family environment are useful in identifying individuals at risk for subthreshold and threshold SAD. With regard to implications for clinical practice, assessment of parental psychopathology and perceived parental rearing may not only help to identify individuals at risk for subthreshold and threshold conditions of SAD, but also help to offer treatment at an early state to prevent them from developing DSM-IV threshold SAD and other, comorbid or subsequent psychopathology.

Acknowledgments The authors thankfully appreciate the helpful comments and suggestions of Jeffrey G. Johnson, PhD, on earlier drafts of this article. This work is further part of the Early Developmental Stages of Psychopathology (EDSP)-Study and is funded by the German Federal Ministry of Education and Research (BMBF) project nos. 01EB9405/6, $01 \mathrm{~EB}$ 9901/6, EB01016200, 01EB0140, and 01EB0440. Part of the field work and analyses were also additionally supported by grants of the Deutsche Forschungsgemeinschaft (DFG) LA1148/1-1, WI2246/1-1, WI 709/7-1, and WI 709/8-1. Principal investigators are Dr. Hans-Ulrich Wittchen and Dr. Roselind Lieb. Core staff members of the EDSP group are: Dr. Kirsten von Sydow, Dr. Gabriele Lachner, Dr. Axel Perkonigg, Dr. Peter Schuster, Dr. Michael Höfler, Dipl.-Psych. Holger Sonntag, Dr. Tanja Brückl, Dipl.-Psych. Elzbieta Garczynski, Dr. Barbara Isensee, Dipl.-Psych. Agnes Nocon, Dr. Chris Nelson, Dipl.-Inf. Hildegard Pfister, Dr. Victoria Reed, Dipl.-Soz. Barbara Spiegel, Dr. Andrea Schreier, Dr. Ursula Wunderlich, Dr. Petra Zimmermann, Dr. Katja Beesdo, Dr. Antje Bittner, Dipl.-Psych. Silke Behrendt and Dipl.-Psych. Susanne Knappe. Scientific advisors are Dr. Jules Angst (Zurich), Dr. Jürgen Margraf (Basel), Dr. Günther Esser (Potsdam), Dr. Kathleen Merikangas (NIMH, Bethesda), Dr. Ron Kessler (Harvard, Boston) and Dr. Jim van Os (Maastricht).

Open Access This article is distributed under the terms of the Creative Commons Attribution Noncommercial License which permits any noncommercial use, distribution, and reproduction in any medium, provided the original author(s) and source are credited.

Conflict of interest S. Knappe, L. Fehm declare to have no conflict of interest.

R. Lieb has received speaking honoria from Wyeth.

$\mathrm{K}$. Beesdo has received speaking honoria from Pfizer.

H.-U. Wittchen has received Research Support from Eli Lilly and Company, Novartis, Pfizer, Schering-Plough. He is currently or has been a consult for Eli Lilly, GlaxoSmithKline Pharmaceuticals, Hoffman-La Roche Pharmaceuticals, Novartis, Pfizer, Wyeth. He has received speaking honoria from Novartis, Schering-Plough, Pfizer, Wyeth.

\section{References}

Alfano CA, Beidel DC, Turner SM (2006) Cognitive correlates of social phobia among children and adolescents. J Abnorm Child Psychol 34:189-201 
American Psychiatric Association (1994) DSM-IV. Diagnostic and statistical manual of mental disorders, 4th edn. Washington, DC

Andreasen NC, Endicott J, Spitzer RL, Winokur G (1977) The family history method using diagnostic criteria: reliability and validity. Arch Gen Psychiatry 34:1229-1235

Arrindell WA, Perris C, Eisemann M, Van der Ende J, Gaszner P, Iwawaki S, Maj M, Zhang JE (1994) Parental rearing behaviour from a cross-cultural perspective: a summary of data obtained in 14 nations. In: Perris C, Arrindell AW, Eisemann M (eds) Parenting and psychopathology. Wiley, New York, pp 145-171

Bandelow B, Torrente AC, Wedekind D, Broocks A, Hajak G, Rüther E (2004) Early traumatic life events, parental rearing styles, family history of mental disorders, and birth risk factors in patients with social anxiety disorder. Eur Arch Psychiatry Clin Neurosci 254:397-405

Beesdo K, Bittner A, Pine DS, Stein MB, Höfler M, Wittchen HU (2007) Incidence of social anxiety disorder and the consistent risk for secondary depression in the first three decades of life. Arch Gen Psychiatry 64:903-912

Bögels SM, van Oosten A, Muris P, Smulders D (2001) Familial correlates of social anxiety in children and adolescents. Behav Res Ther 39:273-287

Chartier MJ, Hazen AL, Stein MB (1998) Lifetime patterns of social phobia: a retrospective study of the course of social phobia in a nonclinical population. Depress Anxiety 7:113-121

Christensen PN, Stein MB, Means-Christensen A (2003) Social anxiety and interpersonal perception: a social relations model analysis. Behav Res Ther 41:1355-1371

Cooper PJ, Fearn V, Willetts L, Seabrook H, Parkinson M (2006) Affective disorder in the parents of a clinic sample of children with anxiety disorders. J Affect Disord 93:205-212

Costello EJ, Angold A, Keeler GP (1999) Adolescent outcomes of childhood disorders: the consequences of severity and impairment. J Am Acad Child Adolesc Psychiatry 38:121-128

Crum RM, Pratt LA (2001) Risk of heavy drinking and alcohol use disorders in social phobia: a prospective analysis. Am J Psychiatry 158:1693-1700

Davidson JRT, Hughes DC, George LK, Blazer DG (1994) The boundary of social phobia: exploring the threshold. Arch Gen Psychiatry 51:975-983

Egger HL, Angold A (2006) Common emotional and behavioral disorders in preschool children: presentation, nosology, and epidemiology. J Child Psychol Psychiatry 47(3-4):313-337

Emmelkamp PMG, Wittchen H-U (2008) Stress-induced and fear circuitry disorders, specific phobias (Chap 4). In: Andrews G, Charney D, Sirovatka PJ, Regier DA, Arlington VAAPA (eds) DSM V. American Psychiatric Publishing, USA (in press)

Fehm L, Pelissolo A, Furmark T, Wittchen HU (2005) Size and burden of social phobia in Europe. Eur Neuropsychopharmacol $15: 453-462$

Fehm L, Beesdo K, Jacobi F, Fiedler A (2008) Social phobia above and below the diagnostic threshold: Prevalence, comorbidity and impairment in the general population. Soc Psychiatry Psychiatr Epidemiol 43:257-265

Fyer AJ, Mannuzza S, Chapman TF, Liebowitz MR, Klein DF (1993) A direct interview family study of social phobia. Arch Gen Psychiatry 50:286-293

Heerey EA, Kring AM (2007) Interpersonal consequences of social anxiety. J Abnorm Psychol 116:125-134

Hettema JM, Neale MC, Kendler KS (2001) A review and metaanalysis of the genetic epidemiology of anxiety disorders. Am J Psychiatry 158:1568-1578

Hudson JL, Rapee RM (2001) Parent-child interactions and anxiety disorders: an observational study. Behav Res Ther 39:1411-1427

Ialongo N, Edelsohn G, Werthamer-Larsson L, Crockett L (1995) The significance of self-reported anxious symptoms in first grade children: prediction to anxious symptoms and adaptive functioning in fifth grade. J Child Psychol Psychiatry 36:427-437

Johnson JG, Cohen P, Kasen S, Brook JS (2006) A multi-wave, multiinformant study of the specificity of the association between parental and offspring psychiatric disorders. Compr Psychiatry 47:169-177

Kabacoff RI, Miller IW, Bishop DS, Epstein NB, Keitner GI (1990) A psychometric study of the McMaster Family Assessment Device in psychiatric, medical, and non-clinical samples. J Fam Psychol 3:341-439

Keenan K, Shaw DS, Walsh B, Delliquadri E (1997) DSM-III-R disorders in preschool children from low-income families. J Am Acad Child Adolesc Psychiatry 36:620-627

Keller MB (2006) Social anxiety disorder clinical course and outcome: review of Harvard/Brown anxiety research project (HARP) findings. J Clin Psychiatry 67(suppl 12):14-19

Kendler KS, Karkowski LM, Prescott CA (1999) Fears and phobias: reliability and heritability. Psychiatr Med 29:539-553

Kessler RC, Merikangas KR, Berglund P, Eaton WW, Koretz DS, Walters EE (2003) Mild disorders should not be eliminated from the DSM-V. Arch Gen Psychiatry 60:1117-1122

Kessler RC, Berglund P, Demler O, Jin R, Merikangas KR, Walters EE (2005) Lifetime prevalence and age-of-onset distributions of DSM-IV disorders in the national comorbidity survey replication. Arch Gen Psychiatry 62:593-602

Lachner G, Wittchen HU, Perkonigg A, Holly A, Schuster P, Wunderlich U, Turk D, Garczynki E, Pfister H (1998) Structure, content and reliability of the Munich Composite International Diagnostic Interview (M-CIDI) substance use sections. Eur Addict Res 4(1-2):28-41

Lépine JP, Wittchen HU, Essau CA (1993) Lifetime and current comorbidity of anxiety and affective disorders: results from the international WHO/ADAMHA CIDI field trials. Int J Methods Psychiatr Res 3:67-78

Lieb R, Isensee B, Von Sydow K, Wittchen HU (2000a) EDSP: an methodological update. Eur Addict Res 6:170-182

Lieb R, Wittchen HU, Höfler M, Fuetsch M, Stein MB, Merikangas KR (2000b) Parental psychopathology, parenting styles and the risk of social phobia in offspring: a prospective-longitudinal community study. Arch Gen Psychiatry 57:859-866

Magee WJ, Eaton WW, Wittchen HU, McGonagle KA, Kessler RC (1996) Agoraphobia, simple phobia, and social phobia in the National Comorbidity Survey. Arch Gen Psychiatry 53:159168

McClure EB, Brennan PA, Hammen C, Le Brocque RM (2001) Parental anxiety disorders, child anxiety disorders, and the perceived parent-child relationship in an Australian high risk sample. J Abnorm Child Psychol 29:1-10

Merikangas KR, Avenevoli S, Acharyya S, Zhang H, Angst J (2002) The spectrum of social phobia in the Zurich cohort study of young adults. Biolog Psychiatry 51:81-91

Milne JM, Garrison CZ, Addy CL, McKeowen RE (1995) Frequency of phobic disorder in a community sample of young adolescents. J Am Acad Child Adolesc Psychiatry 34:1202-1211

Perris C, Jacobsson L, Lindström H, von Knorring L, Perris H (1980) Development of a new inventory for assessing memories of parental rearing behavior. Acta Psychiatr Scand 61:265-274

Reed V, Gander F, Pfister H, Steiger A, Sonntag H, Trenkwalder C, Sonntag A, Hundt W, Wittchen HU (1998) To what degree the Composite International Diagnostic Interview (CIDI) correctly identifies DSM-IV disorders? Testing validity issues in a clinical sample. Int J Methods Psychiatr Res 7:142-155

Ruscio AM, Brown TA, Chiu WT, Saaren J, Stein MB, Kessler RC (2008) Social fears and social phobia in the USA: results from the National Comorbidity Survey Replication. Psychol Med $38: 15-28$ 
Schumacher J, Eisemann M, Brähler E (1999) Rückblick auf die Eltern: Der Fragebogen zum Erinnerten Elterlichen Erziehungsverhalten [Looking back on parents: questionnaire of recalled parental rearing behavior]. Diagnostica 45:194-204

StataCorp (2007) Stata statistical software: release 10.0. Statacorp, College Station

Stein MB, Torgrud LJ, Walker JR (2000) Social phobia symptoms, subtypes, and severity: Findings from a community survey. Arch Gen Psychiatry 57:1046-1052

Stein MB, Chartier MJ, Lizak MV, Jang KL (2001) Familial aggregation of anxiety-related quantitative traits in generalized social phobia. Am J Med Gen 105:79-83

Spitzer RL (1998) Diagnosis and need for treatment are not the same. Arch Gen Psychiatry 55:120

Taylor CT, Alden LE (2006) Parental overprotection and interpersonal behavior in generalized social phobia. Behav Ther 37:1424

Taylor S, Wald J (2003) Expectations and attributions in social anxiety disorder: diagnostic distinctions and relationship to general anxiety and depression. Cogn Behav Ther 32:166-178

Turner SM, Beidel DC, Roberson-Nay R, Tervo K (2003) Parenting behaviors in parents with anxiety disorders. Behav Res Ther 41:541-554

Voncken MJ, Alden LE, Bögels SM (2006) Hiding anxiety versus acknowledgement of anxiety in social interaction: relationship with social anxiety. Behav Res Ther 44:1673-1679

Wakefield JC, Horwitz AV, Schmitz MF (2005) Are we overpathologizing the socially anxious? Social phobia from a harmful dysfunction perspective. Can J Psychiatry 50:317-319

Wilson JK, Rapee RM (2005) Interpretative biases in social phobia: content specificity and the effects of depression. Cognit Ther Res 29:315-331
Wittchen HU, Pfister H (1997) DIA-X-interviews: Manual für Screening Verfahren und Interview; Interviewheft Längsschnittuntersuchung (DIA-X-Lifetime); Ergänzungsheft (DIA-XLifetime); Interviewheft Querschnittsuntersuchung (DIA-X12 Monate); Ergänzungsheft (DIA-X-12 Monate); PC-Programm zur Durchführung des Interviews (Längs- und Querschnittsuntersuchung); Auswertungsprogramm. Swets and Zeitlinger, Frankfurt

Wittchen HU, Fehm L (2003) Epidemiology and natural course of social fears and social phobia. Acta Psychiatr Scand 108(Suppl 417):4-18

Wittchen HU, Perkonigg A, Lachner G, Nelson CB (1998) Early Developmental Stages of Psychopathology study (EDSP): objectives and design. Eur Addict Res 4:18-27

Wittchen HU, Stein MB, Kessler RC (1999) Social fears and social phobia in a community sample of adolescents and young adults: prevalence, risk factors, and comorbidity. Psychol Med 29:309323

Wittchen HU, Kessler RC, Üstün TB (2001) Properties of the Composite International Diagnostic Interview (CIDI) for measuring mental health outcome. In: Tansella M, Thornicroft G (eds) Mental health outcome measures, 2nd edn. Gaskell, London, pp 212-227

Woodruff-Borden J, Morrow C, Bourland S, Cambron S (2002) The behavior of anxious parents: examining mechanisms of transmission of anxiety from parent to child. J Clin Child Adolesc Psychol 31:364-374

Zhang W, Ross J, Davidson JRT (2004) Social anxiety disorder in callers to the anxiety disorders association of America. Depress Anxiety 20:101-106 